\title{
Migrant Networks
}

\section{Citation}

Garip, Filiz, and Asad L. Asad. 2015. "Migrant Networks." Emerging Trends in the Social and Behavioral Sciences: An Interdisciplinary, Searchable, and Linkable Resource: 1-13. doi:

10.1002/9781118900772.etrds0220

\section{Published Version}

doi:10.1002/9781118900772.etrds0220

\section{Permanent link}

http://nrs.harvard.edu/urn-3:HUL.InstRepos:34222819

\section{Terms of Use}

This article was downloaded from Harvard University's DASH repository, and is made available under the terms and conditions applicable to Open Access Policy Articles, as set forth at http:// nrs.harvard.edu/urn-3:HUL.InstRepos:dash.current.terms-of-use\#OAP

\section{Share Your Story}

The Harvard community has made this article openly available.

Please share how this access benefits you. Submit a story.

Accessibility 


\section{Migrant Networks}

\section{Introduction}

Migrant networks are webs of social ties that connect individuals in a sending region to others in a receiving context. Research shows that these networks influence the magnitude and direction of migration flows from the sending region as well as migrants' adaptation outcomes in the destination. This entry summarizes findings on migrant networks from relevant areas of research in anthropology, sociology, demography and economics; identifies the promising lines of inquiry recently undertaken; points to key questions that remain to be investigated; and provides a discussion of recent developments in other fields that may be instrumental to answering these questions.

A focus on migrant networks represents a new approach to migration research, which, until the late 1980s, had been dominated by economic or political explanations of migration. Alternative theories connected migration to wage differentials between sending and receiving countries (or regions within the same country for internal migration), insurance and credit market failures in the sending country, a two-tier occupational structure in the receiving country or exploitative capitalist relations between the sending and receiving contexts.

With Douglas Massey's programmatic article in 1990, however, scholars began to study the 'cumulative causation' of migration - that is, its self-feeding character. The theory posited that each act of migration leads to a series of changes in the sending community, and these changes make future migration more likely. With each new migrant, for example, the migrant networks that connect individuals in the sending and receiving communities expand. More individuals can rely on these networks to migrate; with more migrants, the networks expand further. Through this feedback loop, migration flows become self-sustaining, and are eventually decoupled from the economic or political conditions that initiated them in the first place.

A related line of research studied how migrant networks shape migrants' experiences in the receiving context. Researchers found that migrant networks are a crucial determinant of occupations and wages in the destination, or the flow of money and goods between the origin and destination. Scholars also identified 'ethnic enclaves,' spatially clustered networks of businesses owned by migrants from the same origin, as a relevant unit of analysis in understanding migrants' economic success or failure in the receiving community.

Recent research has conceptualized how migrant networks span a 'transnational' space and sustain economic, political, social and religious activities across national boundaries. This new approach challenges prior work that focuses either on the sending or the receiving country context, and instead points to the links between the two, which are essential to understand where and how migrants strive to achieve social recognition and economic advancement. 
These research areas establish that migrant networks are critical to evaluating the causes and consequences of migration. Analyses of economic or political conditions in the sending and receiving contexts alone are no longer sufficient to understand the drivers and implications of migration; transnational social ties and processes are also a critical component of migration decisions and outcomes.

\section{Foundational Research}

\section{Migrant networks and migration}

Scholars argue that migrant networks facilitate migration by providing access to migrant social capital - that is, resources of information or help that lower the costs and increase the benefits of migrating. Empirical evidence from various settings shows how individuals who have social ties to prior migrants - through family, community, or institutional (e.g. the church) settings - are more likely to migrate themselves and migrate to the same destinations as those who had migrated before them. (Some researchers argue that the process works similarly for refugees (i.e., political migrants), who typically use social ties to other refugees to navigate their passage to a new destination.) Studies also suggest that the expansion of migrant networks and the accumulation of social capital initiate a process of 'cumulative causation,' through which migration flows become selfsustaining.

Cumulative causation theory suggests migration to be a path-dependent process, where the current context of migration depends on previous migration patterns. To capture this process empirically, studies categorized sending communities with respect to their migration prevalence, and observed patterned changes in migrants' characteristics across different phases of community migration. At the early stages of migration from a community, migrants are typically selected from a narrow stratum of the social structure (e.g., from among those who have some education and/or financial resources) that can weather both the costs and the risks of migration while still finding it an attractive undertaking. As migration gains prevalence, migrants become more representative of the community at large. Researchers attribute this declining selectivity of migration to the resources provided by previous immigrants, which increase the net benefits of migration.

\section{Migrant networks and migrants' adaptation in destination}

Research shows that migrant networks often facilitate immigrants' social, political and economic adaptation in the receiving context. Empirical studies have found that newcomers with ties to experienced migrants are more likely to locate jobs, to secure higher earnings, to establish a business, to attempt to legalize and to politically mobilize in destination. Scholars have observed that new migrants often find accommodation or employment, or both, in migrant enclaves - clusters of businesses owned by a particular migrant group. Enclaves typically emerge in close proximity to the areas settled by a migrant group (e.g., Chinatown in New York City), and are thus a staple of many ethnic neighborhoods in migrant-receiving settings. Enclaves - and ethnic networks more generally - provide a locus for political mobilization. Hometown associationsdestination-based organizations that allow migrants to maintain ties with and materially 
contribute to their origin community - also offer places of support to migrants from the same origin.

Additional research has shown that ties to migrant networks increase the likelihood that a new migrant finds employment in the formal sector, which offers higher wages than the informal sector. Studies have also found that migrant networks are more important in determining the employment outcomes of undocumented rather than documented Mexican workers in the United States due to the more vulnerable labor market position of the former. Similarly, among migrants to Germany, scholars have identified migrant networks to be more important for the young and the less educated, or those facing the greatest risk of unemployment. While migrant networks are crucial for a newcomer to locate his or her first job, migrants typically become less likely over time to use migrant networks to find new jobs (with exceptions in some settings, such as Germany), typically drifting away from jobs in the enclave economy.

These findings have led researchers to conclude that migrant networks improve the efficiency and effectiveness of the job search, yielding higher wages especially for new migrants in a receiving context. Researchers have also argued that migrant networks provide benefits to employers, who save time and money in recruiting, training and finding replacement workers since socially connected workers continually support one another. Scholars have also shown that migrant networks can help self-employed migrants navigate labor market uncertainties. Mexican domestic workers in the United States, for example, have been shown to organize and to secure work by collectivizing and sharing information through their migrant networks.

\section{Migrant networks and transnational migrant activities}

Migrant networks influence both the initial decision to migrate from origin, as well as the adaptation outcomes in destination. These networks, however, unravel for some groups as migrants integrate into the receiving community while severing ties to their sending country. But, for other groups, migrant networks continue to support economic, political, social or religious activities spanning both the sending and the receiving contexts. These 'transnational' networks thus provide a new perspective for understanding migrants' social, political and economic adaptation outcomes.

The transnational perspective (or 'transnationalism') offers a corrective to earlier models of migrant adaptation that focus exclusively on the receiving country without considering migrants' ongoing relations with the sending country. Glick-Schiller and colleagues first conceptualized transnationalism in the 1990s as a process by which migrants build a social space linking together their country of origin and their country of settlement. Revised definitions underlined the fluidity of the transnational social space - that is, the fact that it is constantly re-worked through migrants' embeddedness in both the sending and receiving contexts. This embeddedness, in turn, shapes familial, social, economic, religious, political and cultural processes in these contexts.

Scholars have suggested multiple social spaces for study, including migration circuits (migrant networks as well as the resources or ideas that flow through them), transnational 
social formations (the movement of individuals, symbols and resources between settings) and transnational lives. Researchers also recognized the political — as well as scholarlyimplications of the transnational approach: The transnational movement of people (and the goods, ideas and symbols that move with them) may ultimately render state borders obsolete, facilitate the upward socio-economic mobility of impoverished populations and lead to drastically positive changes in gender relations across contexts.

Empirical studies have shown that transnational migrant networks or institutions (such as hometown associations) organize the flow of money and goods (also known as remittances) to families and communities in the sending context (and to migrants in the receiving context). Remittances from international migrants amounted to US\$ 325 billion in 2010 alone, far exceeding the volume of official aid to, and almost reaching the level of foreign direct investment flows in, developing countries. Given the magnitude of these flows, several studies have investigated remittances' impact on poverty and inequality in the migrant-sending regions.

Many studies have suggested that remittances reduce poverty and initiate a development dynamic by relaxing the production and investment constraints in the origin economy; by providing income growth opportunities; or by creating a vessel for risk diversification. Researchers working in different settings find that remittances help migrant-sending families establish small businesses in origin, afford better education for their children, and accumulate wealth.

But researchers have also argued that remittances may produce a cycle of dependency and thus stunt development in the origin. This is especially the case if the funds are used for consumption rather than income- or employment-generating productive activities, hence contributing to a lifestyle that cannot be sustained long-term or through local means. Recent work, however, has found that remittances - even when dedicated to consumption — generate strong 'multiplier' effects in the origin economy.

A related debate has considered the impact of remittances on economic disparities in origin communities. Several studies have found that remittance flows decrease income or wealth inequalities, while others have observed the opposite pattern. Recent work has attempted to reconcile these patterns by showing how the impact of remittances on inequality depends on the cost or past level of migration. In communities where the cost of migration is high (and the level of past migration is low), remittances reach middle- to high-income households and increase inequality. In communities where the cost of migration is low (and/or the level of migration is high), remittances reach lower income households and decrease inequality. These findings - contested in some settingssuggest an inverse $\mathrm{U}$-shaped relationship between migration prevalence in a community and inequality.

While abundant research has examined the impact of monetary remittances, few recent studies have pointed to 'social remittances', or the ideas, behaviors, norms, cultural meanings and social practices that typically travel from the receiving to the sending communities through transnational migrant networks. Researchers have found that 
transnational migrant networks - especially ties to former female migrants - fostered more egalitarian gender norms in origin communities. In some settings, these networks also have helped to diffuse ideas about political participation and civic engagement from the destination to origin communities.

\section{Cutting-Edge Research}

\section{Migrant networks and migration}

There is overwhelming evidence establishing how migrant networks provide information or help to provide resources that increase the migration propensities between origindestination pairs. But recent research has also found that resources from prior migrants are not equally beneficial in all settings nor across all social groups. Studies have shown that ties to prior migrants are a stronger determinant of first than subsequent trips. (In Mexico, these ties are also more important in rural than urban regions.) Studies have also found that prior migrants may not possess sufficient resources to help others due to conditions in destination (such as hostile immigration policies or limited economic opportunities). Migrant networks also operate differently for men and women, leading scholars to demonstrate that the gender composition of the networks is often a key component of the observed migration patterns. In many settings, men (women) benefit more from ties to prior male (female) migrants.

Migrant networks also have differential effects on individuals' migration depending on the diversity of the resources available through them. Having ties to prior migrants with diverse experiences (e.g., in different occupations or destinations) increases the set of options available to potential migrants, and thus increases migration propensities in some settings. Diverse experiences (e.g., to many destinations), however, may also imply the availability of fewer resources in each destination, and as a result, may dampen the positive effect of migrant networks on migration choices.

In high-risk settings - such as international migration requiring border crossing without documents - resources of information or help from trustworthy strong ties (e.g., family members or close friends) are typically more important than those from weak ties (e.g., community members or other acquaintances). In lower risk contexts (e.g., internal migration), however, resources from weak ties - often broader in scope compared to those from strong ties - have a larger effect on individuals' migration propensities.

Individuals lacking the informational or financial resources necessary to migrate to a high-risk context sometimes resort to a stepwise migration strategy. They first draw upon migrant networks in order to migrate to an intermediate destination. Once in this low-risk destination, migrants collect additional resources before attempting a trip to their final destination.

The majority of research has thus focused on migrant networks as channels of information or help from prior migrants that facilitate more migration. A number of recent studies have argued that the visible signs of prior migrants' success (such as 
newly-acquired land or a recently-built house in the origin community) is sufficient to encourage more migration — by demonstrating its efficacy — without any direct information or help from the migrants themselves. Several studies have also shown that migrant networks often act as conduits of normative pressures that make migration more likely. In many sending regions, researchers observed a 'culture of migration,' where individuals come to value migration positively as a rite of passage or an affirmation of identity. In the Mexican setting, for example, researchers have noted the social sanctions exacted on young men who do not attempt a U.S. trip: they are often viewed as lazy and unenterprising, and even undesirable as future mates. In other settings, researchers have connected the increasing mobility of women to the wider acceptability of egalitarian gender norms due, in large part, to earlier female migrants.

In addition to providing resources or creating normative pressures, researchers have also described how migrant networks support the development of migrant institutions, such as smuggling businesses for undocumented border crossing, which facilitate future migration. In the Mexico-U.S. setting, for example, research has found that women are more likely to rely on smugglers to cross without documents compared to men.

While the majority of work has observed positive effects of migrant networks on individuals' migration, few studies have also discussed how certain groups (e.g., women in patriarchal societies) may be denied access to the resources from these networks, or face negative normative pressures related to migration. Research has also argued that migrant networks may impose - possibly non-consensual—social obligations on prior migrants, requiring them to serve as useful resources to potential migrants. Research has also found that migrant networks, by facilitating migration, may lead young adults to give up potential opportunities in the origin (e.g., acquiring education).

\section{Migrant networks and migrants' adaptation in destination}

Countering ample evidence on the benefits of migrant networks for adaptation outcomes in destination, recent research shows that migrant networks may also limit new migrants' opportunities by channeling them into the less profitable, more failure-prone informal ethnic economy. Research has also argued that migrants' immersion in co-ethnic migrant networks may reduce their interactions with non-coethnics, thus impacting their future social and economic adaptation trajectories (by hindering language acquisition or instilling a strong sense of ethnic identity, for example). These negative consequences are especially detrimental for women, who are more likely to take on responsibilities within the home, and are thus less likely to establish ties to non-coethnics through employment.

The negative effects of migrant networks may also accumulate over time and impede the economic mobility of second-generation migrants (i.e., those born and raised in the destination). Portes and Zhou describe a process of 'segmented assimilation,' where migrant networks can lead to alternative paths. For one migrant group, for instance, ties to ethnic networks may result in increasing acculturation and parallel adaptation into the receiving community; another group's co-ethnic ties, however, may imply permanent poverty and relegation to the underclass. Recent empirical evidence from the United States by Kasinitz and colleagues, however, suggests that migrant networks may not 
actually be an impediment to second-generation migrants, as their educational and occupational profiles seem closer to their native counterparts than to their migrant parents.

\section{Migrant networks and transnational migrant activities}

Many researchers celebrated the academic and political implications of the new focus on transnational movement in the migration literature. Recent work, however, has challenged the concept for its lack of innovation and its presumed positive effects for migrants and non-migrants alike. Scholars have noted that transnational theories overlook the role of the state in both facilitating transnational movement (or 'transmigrations') and expediting migrants' incorporation in the receiving context. Scholars have further questioned the notion of 'transnational communities,' arguing that social relations between origin and destination are often fragmented by class, ethnic or other cleavages. Some researchers also raised concerns about the presumed positive effects of transnational relations on gender equality, pointing to the potentially counter effects of agents at local and regional levels.

Scholars have also raised concerns about the premise of the transnational perspective for illuminating empirical patterns. First, researchers criticize the fact that most empirical findings have emerged from Mexico-U.S. migration data. Second, researchers have argued that, in many settings, only an elite minority within each migrant group maintains transnational ties. The remaining majority of migrants eventually become more acculturated, shedding their previous national and cultural attachments - including their mother tongues - while simultaneously integrating more fully into the receiving context.

These concerns notwithstanding, most researchers concede that the transnational perspective, although not new in practice, provides a useful theoretical and analytical lens for understanding migration flows as well as migrants' everyday lived experiences in both origin and destination. In contrast to previous approaches that separately study the causes and consequences of migration, or others that examine migrant adaptation processes only within the receiving context, the transnational perspective encourages scholars to investigate how social, political, economic and cultural processes shape (and are shaped by) the causes and consequences of migration in both the sending and receiving contexts.

\section{Key Issues for Future Research}

While network effects on migration are ubiquitous, most empirical evidence remains correlational. Many studies use survey data to show the (often positive) effects of prior migrants on individuals' migration propensities (or other outcomes, such as, wages in destination), but cannot directly observe the mechanisms - the generative processesunderlying these effects. This oversight raises two concerns. 
First, studies assume the networks effects to be 'social', that is, to reflect true interdependencies between individuals' migration choices, but cannot discard the plausible alternative explanation that those choices may as well be a response to some common and unobserved environmental factor. As Manski argues, this identification problem is common in social science research, where empirical analysis often cannot distinguish 'social' effects (i.e., individuals responding to the behavior or characteristics of the group) from 'correlated' effects (i.e., individuals responding to the same environment).

Second, studies often disagree on what mechanisms explain the observed effects of migrant networks on migration (or other outcomes). Most researchers treat networks as hubs of information or help from prior migrants, while others view them as conduits for normative pressures or other institutionalized resources. Empirical analysis often fails to resolve this ambiguity, as survey data cannot distinguish among alternative mechanisms generating the observed associations.

To address the first problem, future work can follow the recent developments in causal analysis in statistics and econometrics. For example, similar to Munshi, researchers can use instrumental variables estimation, which can isolate network effects from environmental factors (given that the researcher can identify a proper 'instrument', an exogenous factor that influences the network measures but not the outcome of interest). Alternatively, future work can utilize a mixed-methods approach, triangulating evidence from survey data with that from qualitative observations, in order to increase one's confidence in the presence of network effects.

To address the second issue, future work can build on the recent attempts to systematically study the mechanisms of social transmission in networks. Reviewing the network effects literature at large, DiMaggio and Garip posit that there are three potential mechanisms through which networks shape individuals' choices: (1) social learning or facilitation, (2) normative influence and (3) network externalities. Social learning occurs when individuals infer the value of a practice from peers who engage in it, while social facilitation occurs when individuals receive direct assistance from peers that facilitates a practice (for example, migrating or finding a job in destination). Normative influence is present when network peers actively engage in persuading someone to participate or not to participate in the practice, and where the density of ties among those peers determines the extent of their influence. Network externalities are at work when the presence of peers engaging in a practice leads to common resources that increase the value of that practice for the individual.

Applied to the case of migrant networks, social learning or facilitation represents the mechanism most discussed in the literature. Studies describe how prior migrants provide information about or help with migration, making it a less risky and potentially more beneficial endeavor for new migrants. Several studies also suggest normative influence as the generative mechanism for network effects in migration when they, for example, observe a 'culture of migration' in sending regions. Studies also connect migration outcomes to network externalities, although they have not referred to the mechanism as 
such. For example, scholars working on the Mexico-U.S. context have observed how undocumented migrants use smugglers (coyotes) for crossing the border, a common resource whose existence depends on a steady flow of migrants.

Future work can use this typology to consider alternative mechanisms driving the network effects on migration (or migration-related outcomes). No study to date has attempted to distinguish these mechanisms empirically, which is difficult to do with the survey data available to researchers. Thus, future work could focus on collecting qualitative data targeted at understanding the processes through which social ties to prior migrants shape individuals' migration decisions or experiences.

In addition to focusing on how migrant networks influence individuals' migration-related experiences, future research can study how these networks evolve over time. Do migrants increasingly interact with natives of their settlement region? Under what conditions do migrants continue to maintain ties to origin regions?

These questions remain essential to understand how migrant networks form and change, and influence migration streams as well as migrants' transnational experiences. It took a large group of scholars from multiple disciplines to show how migrants' social ties-not just the economic conditions they face in origin or expect in destination - are a crucial determinant of migration outcomes. Future research on migrant networks will continue to be fruitful if scholars from different disciplines come together, closely follow and contribute to the larger discussions in the social science literature related to network effects.

Filiz Garip and Asad L. Asad

\section{Further Readings}

DiMaggio, P., \& Garip, F. (2012). Network Effects and Social Inequality. Annual Review of Sociology, 38, 93-118.

Glick Schiller, N., Basch, L., \& Blanc-Szanton, C. (1992). Transnationalism: A New Analytic Framework for Understanding Migration. Annals of the New York Academy of Sciences, 645, 1-24.

Hagan, J. M. (1998). Social Networks, Gender, and Immigrant Incorporation: Resources and Constraints. American Sociological Review, 63(1), 55-67.

Kasinitz, P., Mollenkopf, J. H., Waters, M. C., \& Holdaway, J. (2008). Inheriting the City: The Children of Immigrants Come of Age. New York: Russell Sage Foundation. 
Manski, C. F. (1995). Identification Problems in the Social Sciences. Cambridge, MA: Harvard University Press.

Massey, D. S. (1990). Social Structure, Household Strategies, and the Cumulative Causation of Migration. Population Index, 56(1), 3-26.

Munshi, K. (2003). Networks in the Modern Economy: Mexican Migrants in the U.S. Labor Market. Quarterly Journal of Economics, 118(2), 549-599.

Portes, A., \& Zhou, M. (1993). The new second generation: Segmented assimilation and its variants. The annals of the American academy of political and social science, 530(1), 74-96.

Waldinger, R., \& Fitzgerald, D. (2004). Transnationalism in Question. American Journal of Sociology, 109(5), 1177-1195.

Abstract: Migrant networks - webs of social ties between migrants in destination and individuals in origin - are a key determinant of the magnitude and direction of migration flows, as well as migrants' adaptation outcomes. The increasing emphasis on migrant networks represents a new approach to migration research, which until the late 1980s, had been dominated by economic or political explanations of migration. This entry summarizes findings on migrant networks from relevant areas of research in anthropology, sociology, demography and economics; identifies the promising lines of inquiry recently undertaken; and points to key issues for future research, such as understanding how migrant networks impact migration behavior and migrants' experiences. Such research into the specific mechanisms of social transmission will need to engage with the on-going discussions on networks effects and their identification in the social science literature at large, and will necessarily require the interdisciplinary collaboration of researchers.

Keywords: migration; social networks; remittances; transnationalism; immigrant adaptation, incorporation or integration

Related articles (discipline, entry title)

Sociology, Assimilation and Its Discontents

Sociology, Global Economic Networks

Sociology, Immigrant Enclaves

Sociology, Social Network Effects on Individual Behavior

Sociology, Transnationalism

Economics, Identifying and Estimating Network Models

Political Science, Migration and Globalization

Anthropology, Social Networks

Anthropology, Migration, Mobility, and Diasporas 


\section{Biographies}

Filiz Garip is Associate Professor of Sociology at Harvard University. Her research lies at the intersection of migration, economic sociology and inequality. Within this general area, she studies the mechanisms that enable or constrain mobility and lead to greater or lesser degrees of social and economic inequality. Her work has been published in Population and Development Review, Demography, Social Forces and the American Journal of Sociology. She is currently working on a book, which will characterize the diversity of the Mexican migrant population in the United States. At Harvard, she has taught courses on migration and economic sociology, and has won the George Kahrl Excellence in Teaching Award from the Department of Sociology. She is currently affiliated with the Weatherhead Center for International Affairs, David Rockefeller Center for Latin American Studies, and the Inequality and Social Policy Program at the Kennedy School. She is also the director of academic programming for the Undergraduate Research Scholars program at the Institute of Quantitative Social Science at Harvard. Garip received her Ph.D. in Sociology and M.S.E in Operations Research \& Financial Engineering both from Princeton University. She holds a B.Sc. in Industrial Engineering from Bogazici University, Istanbul.

\section{Personal webpage \& CV: http://scholar.harvard.edu/garip}

Asad L. Asad is a doctoral candidate in Sociology at Harvard University, where he is also a National Science Foundation Graduate Research Fellow and a Doctoral Fellow with the Multidisciplinary Program in Inequality and Social Policy. Broadly defined, his research interests encompass the fields of crime, law, and deviance; culture; inequality; international migration; political sociology; public policy; and urban sociology. At the intersection of these fields, Asad primarily explores the factors that compel people to migrate internally and internationally, as well as the implications of this mobility for social inequality. His current work draws upon theories of immigrant incorporation to inform the current urban sociological debate about why low-income populations move. Asad earned his B.A. in Political Science from the University of Wisconsin-Madison.

Personal webpage \& CV: http://scholar.harvard.edu/asad 